"Why Volunteer? Evidence on the Role of Altruism, Image, and Incentives" by

\author{
Jeffrey Carpenter \\ And \\ Caitlin Knowles Myers
}

March 2010

MIDDLEBURY COLLEGE ECONOMICS DISCUSSION PAPER NO. 1023

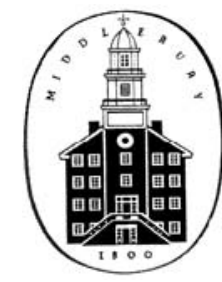

DEPARTMENT OF ECONOMICS

MIDDLEBURY COLLEGE

MIDDLEBURY, VERMONT 05753

http://www.middlebury.edu/ econ 


\title{
Why Volunteer? \\ Evidence on the role of altruism, image, and incentives
}

\author{
Jeffrey Carpenter and Caitlin Knowles Myers*
}

\begin{abstract}
We examine motivations for prosocial behavior using new data on volunteer firefighters that contain a dictator-game based measure of altruism, surveyed measures of other behavioral factors, and call records that provide an objective measure of time spent volunteering. Controlling for a variety of other explanations, we find that the decision to volunteer is positively correlated with altruism as well as with concern for social reputation or "image." Moreover, by utilizing variation in the presence and level of small stipends paid to the firefighters, we find that the positive effect of monetary incentives declines with image concerns, supporting a prediction that extrinsic incentives can crowd out image motivation for prosocial behavior.
\end{abstract}

JEL Classification: C93, D12, J22, D64, D82

Keywords: volunteer, altruism, reputation, extrinsic motivation, firefighter

\footnotetext{
*Associate professor, Middlebury College and research fellow, IZA; assistant professor, Middlebury College and research fellow, IZA. We thank the NSF (SES-Career 0092953) and Middlebury College for funding. In addition, we thank Peter Matthews for very helpful discussion of the theoretic modeling section and John Maluccio and Casey Rothschild for further helpful comments. We also thank Cristina Connolly, Sara Lowes, Marcus Bellows, and Eric Ambrette for highly competent research assistance.
} 


\section{Introduction}

The prominent role of volunteering in the charitable provision of goods and services has helped to motivate a variety of theoretical models of prosocial behavior over the past twenty years. Explanations of why people supply labor seemingly for free have jointly and alternately considered volunteering as a consumption good, as a way of ensuring the provision of a public good, as a means of investing in human capital, as a means of gaining other extrinsic rewards, and as a manifestation of underlying tastes and attributes such as extroversion, altruism, or a desire to look "good" to others (e.g., Menchik and Weisbrod, 1987; Andreoni, 1989; Duncan, 1999; Clary and Snyder, 1999; Ziemek, 2006; Bénabou and Tirole, 2006). However, a lack of appropriate data has left us with a more sparse empirical literature and an incomplete understanding of the extent to which these various possibilities drive volunteerism in practice. Survey-based evidence suggests that wages and income are related to volunteer labor supply (Menchik and Weisbrod, 1987; Freeman, 1997). However, Freeman (1997) finds that a larger determinant of volunteering is simply being asked and concludes more attention should be paid to tastes for prosocial activities, of which there are few measures in existing surveys.

We introduce data from a sample of volunteer firefighters and non-volunteer community members to provide evidence on possible taste-based motivations for volunteering as well as a link between an experimental measure of altruism and a real-world outcome. The data are a combination of information from a survey, a field experiment, and fire department records. The survey provides the usual demographic and income controls as well as measures from personality inventories of traits such as extroversion and risk aversion. We deviate from using only survey measures of personality traits because, along with problems associated with the hypothetical nature of some survey questions, self reports 
may be especially susceptible to what Carpenter (2002) terms idealized persona bias in which a respondent projects the person that he would like to be. We therefore use an experimental measure of altruism via a representative version of the dictator game in which there are real material costs associated with revealing prosocial preferences. ${ }^{1}$ And, rather than relying on self-reports of volunteer labor supply, we utilize call records from fire departments that record which members "turned out" for calls over the course of a calendar year.

We find that altruism is a key motivator in choosing to join the volunteer fire service, which supports the external validity of our version of the dictator game in predicting real-life behavior. However, conditional on selection, altruism plays a role in training hours but not in call response. In contrast to the results for altruism, image concerns, as proxied by having a vanity license plate, are associated with the decision to volunteer and with the visible activity of call response, but not with the less visible activity of training, supporting predictions that the effect of image concerns increases with the visibility of the activity (Nelson and Greene, 2003; Bénabou and Tirole, 2006; Andreoni and Bernheim, 2009). Moreover, we find that paying small stipends to the volunteers increases turnout for some, but that the effect is dampened for those who have greater image concerns. These results confirm recent theoretical predictions that providing extrinsic motivations to volunteers can have unintended negative effects by crowding out image motivations to volunteer (Bénabou and Tirole, 2006).

Although it is not our primary focus, we also present evidence on motivations such as being invited, volunteering to make friends or benefit one's career, and religion. Overall, these factors appear to play a positive role in the decision to become a volunteer, but to have a small or even negative relationship with the amount of time spent volunteering.

\footnotetext{
${ }^{1}$ Experiments are "representative" if the decision problem reflects some aspect of the participant's environment. (See Carpenter et al. (2008) for a discussion.)
} 
We proceed with an overview of theories of prosocial behavior such as volunteering and with a model that incorporates altruism, image concerns, and material rewards into the decision to volunteer. Section 3 then provides a description of the data. In Sections 4 and 5 we examine selection into the fire service and the call turn out of volunteer firefighters. We offer concluding remarks in Section 6.

\section{A model of "turning out"}

Papers in the public finance and labor literatures have traditionally treated prosocial behavior such as volunteering as generating some combination of a public good, consumption good, or investment good (e.g., Menchik and Weisbrod, 1987; Brown and Lankford, 1992; Duncan, 1999). Others have focused more on the role of "pure" and "warm-glow" altruism in motivating volunteers (e.g., Becker, 1974; Andreoni, 1989, 1990, 2006; Bénabou and Tirole, 2006). The differences in terminology- which serve to emphasize the nature of the activity versus the nature of the volunteer-mask what are essentially similar approaches. Whether volunteering is thought of as a public good or as the product of pure altruism, the individual cares only that some level of the good is provided and not who is responsible for the provision; hence, government spending on the public good will "crowd out" private donations of time or money. If volunteering is instead a consumption good or the product of "impure" or "warm-glow" altruism, (Andreoni, 1990) the act of giving itself generates utility for the volunteer, and government provision will not compete to the same extent with private provision. The available empirical evidence suggests that volunteers care both about the level of provision of their product as well as about the act of giving. Government spending appears to at least partially crowd out volunteering (Menchik and Weisbrod, 1987; Brown and Lankford, 1992; Duncan, 
1999; Ziemek, 2006) and in the lab people behave in a manner consistent with a mixture of "pure" and "warm-glow" altruism (Andreoni, 1993; Andreoni and Miller, 1993; Forsythe et al., 1994; Elizabeth Hoffman and Smith, 1994; Palfrey and Prisbrey, 1997; Goeree et al., 2002; Andreoni and Miller, 2002). A third possibility is that there are other extrinsic motivations for volunteering beyond utility gained from the public good created or by the act of giving. One example is investment models in which volunteering is a means of obtaining human capital that will yield returns in the labor market (Menchik and Weisbrod, 1987; Ziemek, 2006).

Like Ariely et al. (2009) we borrow from the model of prosocial behavior developed by Bénabou and Tirole (2006) (BT), which emphasizes the relationship between (pure or impure) altruism, extrinsic motivations, and image concerns. Our model is slightly simpler in that we focus attention on one's interest in maintaining a reputation for prosociality and ignore any other image concerns. While simpler, our version is still sufficient to motivate the issues on which we collect data.

Agents in the model are motivated by three factors: altruistic preferences, extrinsic monetary incentives, and image concerns. Agents with altruistic preferences for the social good place a value, $v_{a}$ on prosocial activities, $a$, like joining the local fire department or "turning out" for individual calls. Agents may receive monetary compensation, $y$, for their prosocial acts (e.g., some firefighters receive modest hourly wages for their efforts) which they value at $v_{y} y$. Lastly, some agents care about their reputation or image in the community according to $R(a, y)$. Combining these three sources of motivation with the cost of engaging in prosocial acts, $C(a)$, we have:

$$
U(a)=\left(v_{a}+v_{y} y\right) a+R(a, y)-C(a) .
$$


The first and last terms in (1) are straightforward especially because we set $C(a)=\frac{k a^{2}}{2}$; however, the image concerns require further elucidation. We assume that an agent's preference type, $\left(v_{a}, v_{y}\right)$, is determined by an independent draw from a bivariate normal distribution and define one's image concern as follows:

$$
R(a, y)=x I_{\Upsilon}(z) E\left(v_{a} \mid a, y\right)
$$

where $x$ determines the extent to which an altruistic act will be visible and $I_{\Upsilon}: z \rightarrow\{0,1\}$ is an indicator function publicly identifying those agents who are motivated by image, $E\left(v_{a} \mid a, y\right)$, or the beliefs of others about the agent's value on prosocial activities. In other words, agents with image concerns comprise a subset $\Upsilon$ of the population.

Substituting (2) and $\frac{k a^{2}}{2}$ into (1) and differentiating yields the first order conditions for the optimal level of prosocial behavior which depend on whether or not image concerns matter.

$$
a k=\left\{\begin{array}{cc}
v_{a}+v_{y} y & \text { if } z \notin \Upsilon \\
v_{a}+v_{y} y+x \frac{\partial E\left(v_{a} \mid a, y\right)}{\partial a} & \text { if } z \in \Upsilon
\end{array}\right\}
$$

For those unconcerned with image the optimal level of prosociality is easy to determine: $a^{*}=\left(v_{a}+v_{y} y\right) / k$.

Solving the first order condition for those agents valuing image is harder than it first appears because it is not simply a matter of evaluating the expectation, $E\left(v_{a} \mid a, y\right)$, and substituting in its derivative. At the heart of the model is a signal extraction problem in which on-lookers need to evaluate the altruistic intentions of the agent $\left(v_{a}\right)$ using the entire decision problem. In other words on-lookers need to anticipate how agents will respond to incentives when they evaluate their actions. 
To see the subtle nature of the problem, we (following BT) exploit the fact that an agent's choice of $a$ reveals a clue about his intentions. The clue, from (3), is that $v_{a}+v_{y} y$ is equal to $a k-x \frac{\partial E\left(v_{a} \mid a, y\right)}{\partial a}$ at the optimum. This means that although one can not determine $v_{a}$ directly from one's choice of $a$, one can make inferences about $v_{a}$ based on $v_{a}+v_{y} y$ because $v_{a}$ and $v_{y}$ are jointly distributed and $y$ is exogenously determined.

Valuation types are distributed $N\left(\begin{array}{c}\bar{v}_{a} \\ \bar{v}_{y}\end{array}, \quad\left[\begin{array}{cc}\sigma_{a}^{2} & \sigma_{a y} \\ \sigma_{a y} & \sigma_{y}^{2}\end{array}\right]\right)$ which means that after considerable calculation ${ }^{2}$, one can derive

$$
E\left(v_{a} \mid a, y\right)=E\left(v_{a} \mid v_{a}+v_{y} y\right)=\bar{v}_{a}+\frac{\sigma_{v_{a}, v_{a}+v_{y} y}}{\sigma_{v_{a}+v_{y} y}^{2}}\left(v_{a}+v_{y} y-\bar{v}_{a}-\bar{v}_{y} y\right)
$$

and after substituting from the first order condition (3) we get

$$
E\left(v_{a} \mid a, y\right)=\bar{v}_{a}+\frac{\sigma_{v_{a}, v_{a}+v_{y} y}}{\sigma_{v_{a}+v_{y} y}^{2}}\left(a k-x \frac{\partial E\left(v_{a} \mid a, y\right)}{\partial a}-\bar{v}_{a}-\bar{v}_{y} y\right) .
$$

Now notice that if we take the derivative of (4) with respect to $a$ we get

$$
\frac{\partial E\left(v_{a} \mid a, y\right)}{\partial a}=\rho k-\rho x \frac{\partial^{2} E\left(v_{a} \mid a, y\right)}{\partial a^{2}} .
$$

where $\rho=\frac{\sigma_{v_{a}, v_{a}+v_{y} y}}{\sigma_{v_{a}+v_{y} y}^{2}}$. With some rearranging, (5) takes the form of a linear differential equation that has the general solution

$$
\frac{\partial E\left(v_{a} \mid a, y\right)}{\partial a}=\rho k+\xi e^{\frac{-a}{\rho x}}
$$

in which $\xi$ is a constant of integration. Lastly, as in BT, because the agent's objective function is well behaved only if $\xi=0$, an interior solution occurs where $\frac{\partial E\left(v_{a} \mid a, y\right)}{\partial a}=\rho k$ and the first order condition for agents with image concerns becomes

\footnotetext{
${ }^{2}$ Following from the fact that if $\left(x_{1}, x_{2}\right) \sim N\left(\begin{array}{c}\mu_{1} \\ \mu_{2}\end{array},\left[\begin{array}{cc}\sigma_{1}^{2} & \sigma_{12} \\ \sigma_{12} & \sigma_{2}^{2}\end{array}\right]\right)$ then $\left(x_{1} \mid x_{2}\right) \sim$ $N\left(\mu_{1}+\frac{\sigma_{12}}{\sigma_{2}^{2}}\left(x_{2}-\mu_{2}\right),\left(1-\varrho^{2}\right) \sigma_{1}^{2}\right)$ where $\varrho$ is the correlation coefficient, $\frac{\sigma_{12}}{\sigma_{1} \sigma_{2}}$.
} 


$$
a k=v_{a}+v_{y} y+x \rho k .
$$

The last thing to do is to evaluate $\rho$ and substitute. This results in the following prediction about the extent to which agents will engage in prosocial behavior.

Proposition 1 There is a unique equilibrium in which prosocial acts depend on one's type, the material incentive and whether or not one is concerned with image. Those not concerned with image contribute at the level $a^{*}=\frac{\left(v_{a}+v_{y} y\right)}{k}$ and those with image concerns contribute $a^{*}=\frac{\left(v_{a}+v_{y} y\right)}{k}+x \frac{\sigma_{a}^{2}+y \sigma_{a y}}{\sigma_{a}^{2}+2 y \sigma_{a y}+y^{2} \sigma_{y}^{2}}$.

Regardless of one's concern for image, altruistic preferences, $v_{a}$, increase one's supply of prosocial behavior. The net effect of the material incentive $y$, however, is only unambiguously positive for acts that are not visible or for those agents who do not worry about their image. Using Proposition 1 we can generate three comparative static predictions which will form the basis of our empirical examination of the behavior of volunteer firefighters.

Corollary 2 Agents with higher altruistic valuations supply more prosocial behavior.

Corollary 3 Agents who do not care about image supply more prosocial behavior when the material incentive increases.

Corollary 4 For agents who care about image and $\sigma_{a y}=0$, an increase in material incentives crowds out the image motivation for prosocial behavior. The net effect of material incentives on the provision of prosocial behavior is ambiguous.

Clearly, the derivative $\partial a^{*} / \partial v_{a}$ is positive indicating that we should expect an unequivocal relationship between one's altruistic preference and volunteer behavior. Likewise, for those people who do not worry about their image, the 
effect of an increase in the material incentive, $\partial a^{*} /\left.\partial y\right|_{z \notin \Upsilon}$, should also be positive. However, once one's image enters into the calculations, the effect of material incentives on prosocial behavior becomes less clear. ${ }^{3}$ If we are willing to consider the BT baseline case of $\sigma_{a y}=0$, then the derivative of interest, $\partial a^{*} /\left.\partial y\right|_{z \in \Upsilon}$, indicates at least partial crowding out of image incentives because the derivative of the image part of $a^{*}$ is negative. That is, providing material incentives for prosocial behavior can crowd out image motivations to perform good deeds. What is unknown is whether the direct positive effect of material incentives is outweighed by the indirect negative effect on image. In the case of our volunteer firefighters, we will see that the two effects are of roughly equal magnitude so that the net effect of material incentives is zero for volunteers with image concerns.

\section{An overview of the data}

Vermont is comprised mostly of rural areas that rely on volunteer fire firefighters to respond to emergencies such as hazardous material spills, vehicle accidents, carbon monoxide alarms, and, of course, fires. Of the 237 fire departments in the state, only 10 are made of up of full-time paid professional firefighters while the remainder rely on volunteers.

In February of 2006 we sent an initial survey to fire chiefs in the state that requested information on the number of firefighters at their department, any compensation paid, annual calls, and training requirements. One hundred twenty nine surveys were returned, yielding a 55 percent response rate. ${ }^{4}$ Based on these

\footnotetext{
${ }^{3}$ The effect of material incenstives is only unclear if the prosocial behavior is visible. If prosocial acts are not publicly visible (i.e., $x=0$ ) then they do not affect image and there is no image crowd-out of material incentives.

${ }^{4}$ We observed no correlation between the size or locations of the towns associated with departments and response rates. We do not know of other data on Vermont fire departments that would allow further exploration of the determinants of response and assume that response is, in fact, not random. However, observations from the initial department surveys do not form the basis for analysis in the paper.
} 
surveys, the time commitment for volunteer firefighters is substantial. Half of departments require that volunteers complete "Firefighter I" training, which requires 144 hours of class time over seven months, before being admitted as a full member. Firefighters who drive department vehicles or seek additional certification in fire fighting, tactical rescue, and other areas of expertise are required to complete additional training. All departments that we contacted also have training sessions that are usually held once a month. In addition to time spent training, volunteer firefighters in the state of Vermont are provided pagers that issue a company-specific tone in the event of a call followed by radio information from the dispatcher. Ideally, firefighters are expected to respond to a tone if they are nearby and able, but in practice there is little oversight and each firefighter decides on a call-by-call basis whether to respond. The number of calls varies by department; the median number of calls in 2005 for our sample was 79 , or roughly a call every four and a half days.

In the summer of 2006 we conducted an experiment and a survey of 205 Vermont volunteer firefighters from 39 departments by both visiting individual stations and by attending the state firefighter convention or "muster." We contacted departments that had responded to our initial survey to ask if they had and were willing to share "call records" for 2005 with the date, time, and nature of each call as well with information on which of the firefighters responded. Not all departments keep or are willing to share such detailed records, but the chiefs of six departments agreed to do so. We then visited these departments during their monthly meetings and passed out fifteen-page experiment/survey booklets for the firefighters to complete, which yielded 143 firefighter observations. We also set up a booth at the annual state muster, which is attended by firefighters from throughout the state, and passed out our materials, yielding another 62 observations, although these cannot be paired with call records from any department. 
So that we could study selection into the fire service, we also conducted our protocol with non-firefighter Vermonters. We purchased a sample of 2000 addresses in the state that were drawn randomly on all criteria save gender. Because firefighters are predominantly male, we chose to oversample males in the community survey. Community members were sent letters with a brief explanation of the protocol accompanied by a booklet that was identical to that distributed to the firefighters with the exception of detailed questions related to firefighting. In order to increase response rates, we also gave them the option of responding online, although only 10 percent did so. Four hundred thirteen community members responded to the full survey. Twelve of these community members happened to be current volunteer firefighters and were added to the sample of firefighters. ${ }^{5}$ Of the remaining 401 community members, 189 reported no volunteer activity and form the control group to which we compare firefighters. The 212 community members who engaged in some other form of volunteer activity were removed from the analysis presented here because it is not clear whether they are an appropriate control group given that, while they are not volunteering for the fire service, they are engaging in other volunteer activities.

Comparing the demographic composition of community respondents to weighted Current Population Survey (CPS) data from December 2006, we see that our sample of community members is similar to both the state of Vermont and to the U.S. more generally. The mean age in the sample of community members, which was restricted to adults aged 18 or older is 48 , while the national and state mean age of adults is 46 . The mean weekly earnings of community members in our sample is $\$ 758$ versus $\$ 743$ in the U.S. and $\$ 615$ in Vermont. Finally, while our sample of non-volunteer community members is 63 percent male, this

\footnotetext{
${ }^{5}$ For the twelve firefighters who completed the community surveys, we are missing information on the firefighter-specific questions that were not included in that version of the survey. In our analysis, these twelve firefighters are included in the probit models of selection into the group of firefighters. However, they are not included in the models of volunteer hours or call response.
} 
reflects the sample design rather than a large gender differential in response rates.

\section{Motivations for Volunteering}

We gathered data on six behavioral motives for volunteering for the fire service. In addition to the two motives that the model focuses on (altruism and image), we asked survey questions about career concerns, using the fire service to make or be with friends (or being an extrovert in general), one's attitude towards risk, and volunteering to comply with religious beliefs. The details are as follows. ${ }^{6}$

Our proxy for altruism comes from a field experiment based on the original dictator game (Forsythe et al., 1994) and a version in which a context similar to the decision to volunteer was emphasized (Eckel and Grossman, 1996). In the original dictator game, subjects are asked to donate to a random participant selected by the experimenter. There has been some debate about how to interpret the resulting donation. Donations may be motivated by altruism, but may also reflect an "experimenter effect" arising from the experimenter's ability to observe the subjects' actions (Elizabeth Hoffman and Smith, 1994). We implement a modified version of the dictator game based on Eckel and Grossman (1996) in which the subjects' actions are more clearly linked to altruism. In our version of the game, participants were first asked to pick among thirteen charities or write in a charity of their choice. They were then asked to decide how much of a $\$ 100$ endowment to transfer to their chosen charity. Given the large expected sample size, each participant was told that we would randomly implement $10 \%$ of the allocation decisions after they were all collected, yielding an expected payoff of $\$ 10$ if all of the money was kept. After the collection phase was finished we wrote checks to the charities for the total amounts donated and,

\footnotetext{
${ }^{6}$ For the sake of length, we only highlight the design of our experiment and survey. A copy of the survey booklet is available at either of the authors' websites.
} 
to preserve the anonymity of their responses, we sent unnamed VISA gift cards for the residual shares of the $\$ 100$ to the chosen decision-makers. Obviously, we could not run the experiment double blind because we needed to send the chosen decision-makers the money that they decided to keep and we needed to match the experiment and survey data to the call records for the firefighters. That said, we tried to make the decision as anonymous as possible. In addition to the unnamed gift cards, participants were always referred to by an anonymous alphanumeric code, they were explicitly told not to write their names anywhere on the booklets and, during the firehouse visits, participants returned their completed booklets in a covered box near the back of the room away from the experimenters.

By allowing the subjects to choose from among a long list of charities or even to write one in, we greatly increase the chances that a given subject will be able to donate to a recipient that they feel is deserving. Eckel and Grossman (1996) show that when subjects are provided with this type of context, donations increase, suggesting that the dictator game allocation is motivated by altruism.

Figure 2 presents a histogram of charitable allocations in the dictator game for volunteer firefighters, volunteer community members, and non-volunteer community members. We use the amount allocated to charity as a proxy for altruism in the analysis that follows. ${ }^{7}$ Volunteer firefighters and volunteer community members have similar outcomes in the dictator game, and both groups tend to donate more than the non-volunteer community members. The mean donation for the firefighters was $\$ 77.35$, while that for volunteer community members was $\$ 76.20$, and the difference is not statistically significant $(\mathrm{t}=.7399$, $\mathrm{p}$-value $=0.4598)$. The non-volunteers, by contrast, have a mean allocation of $\$ 67.92$, which is significantly different from the allocation of either volunteer

\footnotetext{
${ }^{7}$ If we instead include an indicator for the respondent giving all of the money to charity, the results in the next two sections are similar.
} 
group. (P-values for pairwise tests of mean allocations for the two volunteer groups versus the non-volunteers are both less than 0.05.) The similarity between the distribution of allocations for the two volunteer groups (KolmogorovSmirnov test yields a p-value of 0.742 , indicating no significant difference between the distributions) is noteworthy for two reasons. First, it supports the decision to exclude the volunteer community members from the models of selection into volunteer firefighting that follow. Second, the similarity in outcomes also is consistent with the assumption that the slight change in protocol for firefighters and community members (i.e., visiting the stations versus mailing the booklets) did not have a noticeable effect on allocations. ${ }^{8}$

The second motivation for volunteering that we consider is concern for one's image. As with altruism, an indirect and less obvious approach to measuring image concerns seems more likely to yield an accurate measure. Instead of asking directly whether a participant valued his or her reputation in the community, we asked a question designed to determine whether he or she chose to display information about him or herself to others. When people in the state of Vermont register their automobiles they are randomly issued a license plate but can chose to pay more to receive a "vanity plate," which has special lettering or of the addition of a special placard. Examples of possible placards include endangered animals on the "Conservation" plate, children's drawings on the "Building Bright Futures" plate, the purple heart medallion issued to wounded soldiers or the international symbol of the Freemasons. We asked whether our

\footnotetext{
${ }^{8}$ This assumption is further supported by two observations. First, the 12 volunteer firefighters who were picked up in the community surveys have a mean dictator game allocation of $\$ 77.29$, which is quite similar to the mean of $\$ 78.33$ observed for the firefighters who were surveyed in person. The distributions of their allocations are also similar, although the very small sample of firefighters from the mail survey precludes statistical inference. Second, although our selection equations focus on a comparison of the volunteer firefighters to the non-volunteer community members, we note that we obtain similar estimates of the relationship between the dictator game allocation and the propensity to volunteer when comparing volunteer community members and non-volunteer community members, who both completed the mailed surveys.
} 
participants purchased such a vanity plate for their vehicles. There are a variety of placards available to all Vermonters and we intend ownership of a vanity plate to be a proxy for image concern for both community members and firefighters. However, most firefighters select the placard shown in Figure 1. Displaying the maltese cross on one's vehicle broadcasts to everyone that the driver is a person that volunteers a lot of time to the community. It is also important to note that the placard in Figure 1 does not help volunteers respond to tones quickly because most volunteer firefighters purchase warning lights and sirens for their personal vehicles for this purpose. In other words, there are ways to be modest about one's involvement (e.g., by installing dashboard-mounted rather than roof-mounted flashing red lights on a personal vehicle) but spending more on the plate in Figure 1 is not one of them.

We also considered other, un-modeled, reasons why people might volunteer for the fire service. It might be the case, for example, that people think that volunteering will enhance their performance on the job or help them get a job (Clary and Snyder, 1999). To asses this motive we asked about the degree to which respondents agreed with three statements about the career impacts of volunteering. People might also volunteer because they are extroverts and the fire service allows them a new opportunity to interact with other people. In addition to two direct questions about making friends or having friends already in the fire department, we asked participants to respond to five extroversion statements borrowed from the NEO personality inventory (Costa and McCrae, 1992). Interior fire fighting is not the only risky endeavor facing volunteers; simpler tasks like ventilating a roof can become dangerous when certain circumstances are accounted for (e.g., height, pitch, roofing material, weather). It might, therefore, be reasonable to believe that risk seekers are more likely to join. We included six statements from the Weber et al. (2002) risk assessment scale to assess each individual's willingness to engage in behaviors that were 
risky to one's health (e.g., bungee jumping). The last factor that we thought might motivate a person to volunteer for the fire service is his commitment to religion. Because many religions preach service to one's community, we asked participants to rate how religious they were and we asked them how often they attended religious services.

In addition to the behavioral measures that we focus on, we collected an extensive set of demographics and two factors that we either thought would be particularly important in this situation or have been discussed before. Many fire departments in Vermont are associated with long family traditions and many people join because of family connections. Because of this we gathered information on whether a respondent currently has or has had a family member in the fire service (family $f f$ ). Freeman (1997) found that one of the biggest indictors of whether or not one volunteers is whether the person had been explicitly asked to serve. We asked a similar question (invited).

Table 1 provides a description of the variables used in the analysis as well as their means for volunteer firefighters and non-volunteer community members. For inventories in which participants responded to a number of statements (career concerns, extroversion, attitudes towards risk), we summarize their motives via factor analysis. Looking at differences in means, we see that, relative to non-volunteer community members, volunteer firefighters score higher on all behavioral measures that we expect to contribute to a proclivity for prosocial behaviors. Firefighters allocate more to charity in the dictator game, are more likely to have a vanity plate, and score higher on inventories of career concerns in volunteering, social concerns in volunteering, extroversion, and risk. Firefighters are also more likely to be religious, to have family members who are firefighters, and to have been invited to join the department. Moreover, all differences in behavioral factors between firefighters and non-volunteer community members are significant with p-values below 0.01 . 


\section{Estimates of volunteering}

Table 2 presents the results of a probit analysis in which the dependent variable indicates whether a respondent belongs to our sample of volunteer firefighters or non-volunteer community members. In Model 1 we provide estimates of the relationship between the decision to volunteer and various potential motivations (altruism, image concerns, career concerns, social concerns and extroversion, risk attitudes, religiosity, family in the fire service, and an indicator for being invited). We increase the number of variables in Model 2 to include demographic controls for age, gender, marital status, children, educational attainment, student status, employment status, income, wages, Vermont nativity, charitable donations, and distance from residence and workplace to the local fire department. Model 3 introduces instruments for altruism that are described in greater detail in the following sub-section.

The effect of altruism in Model 1 is positive and indicates that an approximate one standard deviation increase in the dictator game allocation $(\$ 30)$ is associated with a 5 percentage point increase in the probability of belonging to the sample of volunteer firefighters. In addition, respondents with vanity plates, our proxy measure of image concerns, are 14 percentage points more likely to be firefighters. We find that a one unit increase on the 1-5 Likert scale question "Volunteering is a good way to make friends" is associated with a 15 percentage point increase in the probability of volunteering. The point estimates also suggest that extroversion is positively correlated with becoming a firefighter, but the coefficient is not significant. Career concerns, a taste for risk, and religionsity are also positively associated with selection into firefighting. Finally, as expected, having family members who have been firefighters and being invited to join the local department have a strong positive relationship with firefighting.

The coefficient on our proxy for altruism in Model 2, which includes ad- 
ditional demographic controls, is identical to that in Model 1, but, because the standard error increases slightly (perhaps due to the reduction in sample size due to missing observations of added variables), it is no longer significant $(p=0.155)$. The relationship between image, volunteering to make friends, religion, having family members who are firefighters, and being invited remain quite similar. We see trends in some of the other measures of behavioral motivations that suggests that they are not robust to the addition to demographic controls; the coefficient on career concerns has become negative and insignificant and the effect of having friends on the department now appears to be negative. Unreported coefficients for the demographic controls are, overall, as expected. We estimate that younger individuals, men, and those without children at home are more likely to volunteer, which is not surprising given that the fire service has traditionally been male-dominated and that volunteer firefighting can be physically rigorous, time intensive, and unpredictable.

\section{Potential Instruments}

Observing correlations between self-reported attitudes or lab-based behavior and volunteering provides evidence on how volunteers differ from non-volunteers and how work in the lab relates to real life. Researchers typically treat attitudinal measures such as altruism as exogenous. This seems reasonable in laboratory experiments of short duration, but outside of the lab repeated prosocial behaviors may have feedback effects in which they, in turn, affect attitudes. In the context of this paper, altruism may motivate volunteers, but volunteering may also positively or negatively influence altruism. This possibility has not been examined previously and there is little existing evidence on potentially valid instruments. We include several questions aimed at providing possible instruments for altruism, which should relate to the formation of a respondent's altruistic attitudes prior to selecting into firefighting, but should not otherwise 
be related to that decision.

Previous evidence has demonstrated the inter-generational transmission of generosity (Mark Wilhelm and Steinberg, 2008). After each respondent chooses his allocation in the dictator game, we asked each how much he thought his mother would have allocated in the same situation (mother allocation) with the idea that parental altruism will have affected child altruism via some combination of "nature" and "nurture." 9 However, it is possible that respondents would tend to simply attribute their decision in the experiment to any other participant, yielding what psychologists would term "false consensus bias." To control for this possibility, we also asked what the respondent thought a random participant would donate (random participant allocation). Conditional on our control for false consensus bias, we expect that mother's altruism will have influenced child's altruism, but that it will otherwise not directly be related to the decision to volunteer.

In addition, we asked respondents if they had ever participated in the Boy or Girl Scouts of America as children (scout). Both scouting organizations are popular national movements that incorporate values related to altruism. The Boy Scouts of America states that the organization's mission is to "prepare young people to make ethical and moral choices over their lifetimes by instilling in them the values of the Scout Oath and Law," which include the promise to "help others at all times" and the statement that a scout is, among other things, "helpful, friendly, courteous, and kind" (Boy Scouts of America, 2007). The Girl Scouts, a separate organization, has a stated program goal that includes encouraging scouts to "relate to other with increasing understanding, skill, and respect." Girl Scouts recite a promise "to help people at all times"

\footnotetext{
${ }^{9}$ Using measures of charitable giving from the Panel Study of Income Dynamics, Mark Wilhelm and Steinberg (2008) find an intergenerational correlation in generosity. In a similar vein, Dohmen et al. (2006) find that attitudes towards trust and risk are transmitted from parents to children.
} 
(Girl Scouts of America, 2007). To the extent that children typically select into these organization at a young age (Boy Scouting begins at age 11 and Girl Scouting at age 7) and with the support of a parent, we anticipate that membership indicates exposure to teaching aimed to increase altruism but that this is unlikely to be otherwise correlated with volunteering as an adult.

Column 3 of Table 2 reports the results of an instrumental variable probit model of selecting into firefighting using mother allocation, random participant allocation, and scout to instrument for altruism. The marginal effect of the dictator allocation when instrumented is highly significant and more than twice as large as in the previous models; a one standard deviation in the allocation is associated with a 15 percentage point increase in the probability of volunteering. While the relationship between altruism and volunteering was also positive in uninstrumented models, the instrumental variables results suggest that the effect of altruism is of a more similar magnitude to that of reputation, a desire to make friends, and religiosity. One possible explanation for this result is that there is something about the act of volunteering itself that actually tends to decrease altruism or the measurement of altruism via the dictator game.

We carried out a range of diagnostic tests to assess the validity of these instruments. Looking at an (unreported) first stage regression of the dictatorgame allocation on mother allocation, random participant allocation, and scout as well as the remaining exogenous variables from Model 2 for the decision to volunteer, we see that the first two are individually significant while the coefficient on scouting has a p-value of 0.36. As expected, there is a positive correlation between the dictator game allocation of a respondent the allocation s/he predicts his mother would make, even controlling for the possibility of projecting one's level of altruism onto others. Respondents who were scouts as children give an average of $\$ 3.17$ more in the dictator game. The three instruments are jointly significant with a p-value that is less than 0.001 . 
A Wald test of exogeneity rejects the null with a p-value of 0.012 , suggesting the need to instrument for altruism. We also performed a Hausman test, but in this case the rank of the differenced variance matrix did not equal the number of coefficients being tested and we were unable to rely on the test statistic. However, a Hausman test for a simple model with only altruism in the righthand side indicates that the two models are statistically significantly different. Moreover, although we cannot assess statistical significance of the difference between the overall models, the point estimates of the coefficient on altruism are more than twice as large when instrumented.

We performed a Amemiya-Lee-Newey test of overidentification and fail to reject the null hypothesis that the instruments are uncorrelated with the error term in the selection equation. Hansen's J test also fails to reject the null when using a linear probability instrumental variable model. Taken as a whole, the results suggest that it may be necessary to endogenize altruism and we believe that we have appropriate instruments for doing so.

However, even if this is not the case, we believe that the simple correlation between altruism and volunteer behavior is a novel result of significant interest. Establishing the external validity of an experiment like our dictator game may have value for future research that attempts to bridge the existing lab experimental literature and behaviors of traditional interest to economists (e.g., labor supply, contract compliance...). The positive relationship between altruism and volunteering remains even in uninstrumented models, indicating, at the very least, that there is a positive relationship between altruism as measured by an experiment and volunteering in real life.

We also note that, like altruism, other behavioral motivations may be endogenous. The possible endogeneity of image concerns as proxied by having a vanity plate is of special concern. Although we do not have potential instruments for image, we argue that we can rule out two of the more obvious ways 
in which it might be endogenous via omitted variable bias or reverse causality.

First, because firefighters, like all individuals, must register their vehicles and select and pay for their plates themselves, it is not the case that vanity plates can be given as a reward for service. Second, it does not appear to be the case that the act of volunteering itself influences image concerns. If this type of reverse causality were present, we would expect the relationship between image and volunteering to vary with years of experience as a volunteer. However, the estimated coefficient on image in the intensive labor supply models that follow is robust to the addition of a control for experience, and if we interact experience with image, the estimated coefficient on the interaction is small and statistically insignificant. ${ }^{10}$

\section{$5 \quad$ Estimates of turnout}

The data include both a subjective and objective measure of the level of participation in the volunteer fire service. First, we asked firefighters to estimate their average monthly hours spent on training and other fire-related "work." Second, we obtained call records from six participating departments that listed details of each call and which firefighters responded. We are able to match 122 firefighters from our survey to these call records.

\section{Using self-reported hours}

Table 3 reports the results of separate log-hours regressions of firefighter-estimated training and call hours. Interestingly, altruism appears to be positively associated with training hours but not with call hours while image is positively

\footnotetext{
${ }^{10}$ We choose not to include experience in the models of intensive labor supply because in theory it might also be regarded as an outcome variable that is affected by behavioral motivations. However, in practice, the results of interest are robust to the inclusion or exclusion of this variable. One might also wish to interact altruism with experience to test for reverse causality. However, altruism is not a statistically significant predictor of intensive volunteer labor supply and, not surprisingly, the coefficient on an interaction between altruism and experience also is not statistically significant.
} 
associated with call hours but not with training. Responding to calls (in uniform on a large red truck with blaring sirens) is presumably far more visible than training (which usually takes place inside the station or in the station parking lots). The results, which are similar using instrumental variables techniques, suggest that altruism plays a larger role in the less-visible venue while image plays a larger role in the more-visible one. However, overall our models had little explanatory power and most coefficients were insignificant. This may reflect a lack of variation in self-reported hours. The 25 th and 75 th percentiles of usual monthly training hours were 4 and 11 hours. The 25 th and 75 th percentiles of usual monthly call hours were 8 and 25 hours.

The lack of explanatory power may also result from errors in self-reporting. Using the call records and call durations, we reconstruct individual firefighters' actual average monthly hours spent on call response and compare them to their self-reported hours. We report the difference in actual and self-reported hours in Figure 3. The average firefighter self-reports spending nine more hours per month on non-training work than we observe for him using call records and, as the distribution shows, a large majority (91 percent) of firefighters substantially overestimate their hours. This is exactly the sort of self-reporting bias that worries us about previous estimates of volunteer labor supply.

Given the likely error in self-reported hours, the positive relationship between image and call hours in Table 3 may reflect a tendency of those with image concerns to overstate their actual involvement in the fire service. To test this, we regress each firefighter's "error- in self-reporting his hours on the variables listed in Table 3 as well as on image only. In neither case do we find a significant relationship between reputation or other characteristics and the error in reporting hours. The discrepancy between self-reported hours and call hours may also result from firefighters including non-call related fire work such as community outreach or equipment maintenance in their self-reports. If we use actual 
call hours rather than self-reported hours, the (unreported) results are similar to those in Table 3, although the magnitude of the reputation effect is smaller when using actual call hours. We conclude that although self-reported hours are a problematic measure of volunteer labor supply, the relationship between altruism and less-visible activities and reputation and more-visible activities is robust.

Using an objective measure of call response

To our knowledge, previous studies of volunteerism all have relied on selfreported volunteer hours, which in our case appear to be overestimated. To provide a more objective measure, we use station call records for calendar year 2005. The data form an unbalanced panel in which each observation records whether an individual firefighter responded to a particular call. ${ }^{11}$ Because firefighters don't know in advance how long any given call will take, response may be a more accurate measure than total call hours. Tables 4 and 5 report the results of several specifications of a random effects call response model. Overall, models using the objective measure appear to have greater explanatory power than those using self-reported hours. As we found using self-reported call hours, the effect of altruism is quite small and insignificant across models and, not surprisingly, tests of instrumental variable models do not suggest that we need to instrument for it. We also choose to use a linear probability model rather than a random effects probit model both to avoid potential instability in the use of quadrature and to avoid difficulty in interpreting and calculating standard errors for interaction terms (Ai and Norton, 2003). Fewer than 2 percent of predictions fall outside of the $[0,1]$ range and standard errors are corrected for

\footnotetext{
${ }^{11}$ Stations with more calls are over-represented in this panel. Controls are included for station-specific effects as well as for call volume and spacing. A separate balanced sample was also created by randomly selecting calls for each firefighter so that the number across firefighters is the same. Results using the balanced sample are not substantially different than those presented here.
} 
heteroskedasticity induced by the linear model. Moreover, the marginal effects presented in Tables 4 and 5 are quite robust to model specification; we get similar estimates using random effects probits and instrumented probits as we do with the random effects linear probability model that we present.

Table 4 presents three models of call response. In Model 1 we control only for characteristics of the call, call history, and department fixed effects. We find that firefighters are less likely to respond to calls during typical work hours or in the middle of the night. Call response is decreasing in the number of calls in the past week, suggesting the presence of physical fatigue or of diminishing marginal utility of responding to calls within a narrow window of time. As any volunteer firefighter could tell us, turnout is higher for calls for any sort of fire as opposed to vehicle accidents, alarms, etc. In Model 2 we add measures of different explanations for prosocial behavior and in Model 3 we add demographic controls as well. Altruism as measured by the dictator game allocation positively influences selection into the fire service, but does not have a significant effect on call response conditional on selection. Image, however, continues to be positively correlated with prosocial behavior; firefighters with a vanity plate are 12 percentage points more likely to respond to a call than those without. Endogeneity, however, is a concern; it may be the case that firefighters who are more involved in their stations are more likely to purchase a vanity plate that displays their status. Career is also positively associated with call response. Interestingly factors such as a desire to make friends and religion that were positively associated with the decision to volunteer have negative (but insignificant) relationships to call response, suggesting that they may motivate selection into volunteering but not the supply of volunteer hours.

In Table 5 we introduce controls for extrinsic incentives. There is substantial variation across volunteer fire departments in Vermont in the presence and level of small stipends paid to firefighters. Many departments offer no recompense 
for the firefighters' time. However, others have a small pot of money that is divided annually among the firefighters. Others pay an hourly stipend for time spent on calls. These payments are unlikely to exceed the direct costs of participation in volunteer departments. Seventy percent of departments in our initial survey offer no compensation and, among those with an hourly wage for calls, the mean is 8.34 , far below the mean salaries of firefighters who are often leaving work to respond to calls. Moreover, training time is not compensated by any departments and firefighters are responsible for purchasing the lights and sirens for their personal vehicles, which cost several hundred dollars. We use two alternative measures of extrinsic incentives: the amount of any stipend paid (Model 4) and a dummy variable indicating the presence of a stipend (Model 5). Because the presence and level of stipends are colinear with the six departments represented in the sample, we remove the department indicators and replace them with a measure of annual call volume, which is likely an important determinant of call response that was controlled for previously with the station indicators.

We are particularly interested in whether the interaction between extrinsic incentives and reputation is negative, as predicted by the model. Although we are concerned that image and stipend could potentially be endogenous, the interaction terms in Models 5 and 6 are less likely to be inconsistent. For this to occur, we would need a story in which the interaction between image and stipend is correlated with the error term once the direct effects of the two variables (and other observables) have been partialled out. It is quite difficult to come up with such a story. An example would be that plates are substitute for stipends as rewards for volunteer service. In this case firefighters with vanity plates but no stipends would have greater volunteer labor supply than firefighters with vanity plates and stipends. However, we have already pointed out that such a story is impossible because plates must be obtained and paid for by the 
individuals who will use them.

We find that the image concerns and the presence of a stipend are both positively associated with turning out to a fire call. In Model 5 , firefighters with a vanity plate are 28 percentage points more likely to respond to a call than firefighters without one, and firefighters who are paid an hourly stipend are 16 percentage points more likely to respond to a call than firefighters who are not paid a stipend. But the positive effect of a stipend is canceled for firefighters who have vanity plates; the effect of a stipend for those with image concerns is effectively zero. Looking at Model 4, in which the level rather than the presence of a stipend is used, we see essentially the same result. For a $\$ 1$ increase in the level of a stipend, firefighters who do not have vanity plates are 2 percent more likely to turn out to a call. The marginal effect of a stipend for firefighters who have vanity plates, however, is not significantly different from zero. The negative coefficients on the interactions terms indicate that for firefighters with image concerns the positive direct effect of small extrinsic incentives is canceled by the negative indirect effect of incentives on their image for altruism.

\section{Conclusion}

We have introduced unique data on volunteer firefighters and non-volunteer community members that combine survey measures of demographic and behavioral attributes with a measure of altruism generated by the dictator game. The data also include an objective measure of volunteer labor supply for the firefighters via departmental call records. Using these data, we are able to test the predictions of a model in which prosocial behavior is determined by a combination of altruism, image concerns, and extrinsic motivations.

We find that altruism as measured by the dictator game plays a role in the real-life decision to volunteer, and that it also is positively correlated with 
firefighter training hours. However, altruism does not appear to influence a firefighter's decision to respond to a call, suggesting that altruism is not an important motivator in the level of provision of the more visible of the two firefighting activities. Image concerns as proxied by having a vanity license plate, on the other hand, are positively associated both with the decision to volunteer and with call responses.

Recent research has focused on the potential impacts of offering extrinsic incentives for prosocial behavior. We are able to offer empirical evidence on this by taking advantage of variation in the presence and level of small stipends paid to volunteer firefighters in Vermont. We find that offering such extrinsic incentives to volunteers has the direct effect of increasing call response. However, this effect is negated for volunteers with image concerns; offering extrinsic incentives to this group has zero net effect on their volunteer labor supply. This result suggests that policy makers and volunteer organizations wishing to influence prosocial behaviors should account for the complex interplay of extrinsic incentives and image. Volunteers may value monetary rewards, but such rewards can also have the indirect and presumably unanticipated effect of discouraging prosocial behavior among those who care about being perceived as altruistic.

Turning to other factors, we find that social and career concerns, a desire to make friends, religion, and being invited all play a positive role in the decision to volunteer. However, they have a much smaller- and possibly negative- relationship to the decision to turn out for a call. As with altruism, what motivates an individual to become a volunteer does not necessarily carry through to greater time devoted to volunteering. 


\section{A Appendix: Protocols for the behavioral variables}

\section{Altruism as measured by Dictator Game}

\section{Splitting $\$ 100$}

We begin the survey with a three-part decision-making task that involves real money. In this task you will allocate $\$ 100$ between yourself and a charity of your choice. You will simply decide how much of the $\$ 100$ you want us to send directly to you and how much you want us to send to the charity. The funds for this part of the survey have been provided by the National Science Foundation. We expect that 500 people will respond to this survey. When we have collected 500 responses we will randomly pick 50 people and implement their decisions. This means that you have a 1 in 10 chance of having your choice implemented. In other words, for 1 in 10 people we will send you and/or the charity that you select actual money. Therefore, you should consider your choices carefully. The first thing that you will do is choose a charity. Then you will choose how to allocate $\$ 100$ between yourself and the charity that you picked. If you are one

of the 50 chosen participants, your choice will be implemented and you and/or your charity of choice will receive the amounts of money that you have selected.

Part A:

Please choose the charity that you want to receive your donation.Pick one of the following charities or write in a charity at the bottom:

o American Red Cross

o $\quad$ United Way

o $\quad$ Vermont Public Radio

o Amnesty International 
o American Cancer Society

o $\quad$ Doctors without Borders

o United Service Organizations (USO)

o UNICEF

o $\quad$ Vermont Land Trust

o Humane Society of the United States

o Habitat for Humanity

o The Nature Conservancy

o American Diabetes Association

o Other:

Part B:

Choose the amount of money that you want us to allocate to the charity of your choice. The remaining money will be sent in the form of an anonymous VISA gift card directly to you.

Allocate __ of the $\$ 100$ to my charity of choice and send the rest to me.

\section{Career Questions}

For each of the following statements, please indicate how strongly you agree using the scale provided below.

\section{1:Strongly Disagree 2:Diagree 3:Neither 4:Agree 5:Strongly Agree}

In general, it looks good to have volunteering on your resume.

Volunteering can help me to develop skills that will benefit me in my chosen profession.

Volunteering can help me make contacts that are important to me professionally. 


\section{Extroversion Questions}

On the following pages there are phrases describing people's behaviors. Please use the rating scale below to indicate how accurately each statement describes you. Describe yourself as you generally are now, not as you wish to be in the future.

\section{1:Very Inaccurate 2:Inaccurate 3:Neither 4:Accurate 5:Very Accu-} rate

Feel Comfortable around people.

Make friends easily.

Am skilled in handling social situations.

Don't like to draw attention to myself.

Talk to a lot of different people at parties.

\section{Risk Questions}

For each of the following statements, please indicate your likelihood of engaging in each activity or behavior using the scale provided below.

\section{1:Very Unlikely 2:Unlikely 3:Neither 4:Likely 5:Very Likely}

Going down a ski run that is beyond your ability or closed.

Going whitewater rafting during rapid water flows in the spring.

Not wearing a seat belt when a passenger in the front seat.

Periodically engaging in a dangerous sport (e.g., mountain climbing or sky diving).

Trying out bungee jumping at least once.

Piloting your own small plane, if you could. 


\section{Religion Questions}

Please rate your religious outlook.

o Religious

o Somewhat religious

o Not very religious

o Not religious

o Don't know

How often do you attend organized religious services?

o Never

o $\quad$ Rarely

o Occasionally

o Regularly

o Very often

A complete version of the survey booklet is available at both authors' websites. 


\section{References}

Chunrong $\mathrm{Ai}$ and Edward C. Norton. Interaction terms in logit and probit models. Economics Letters, 80(1):123-129, 2003.

James Andreoni. Philanthropy. In Serge-Christophe Kolm and Jean Mercier Ythier, editors, Handbook of the Economics of Giving, Reciprocity, and Altruism, volume 2. North Holland, 2006.

James Andreoni. Giving with impure altruism: Applications to charity and ricardian equivalence. The Journal of Political Economy, 97(6):1447-1458, 1989.

James Andreoni. Impure altruism and donations to public goods. The Economic Journal, 100(401):464-467, 1990.

James Andreoni. An experimental test of the public-goods crowding-out hypothesis. American Economic Review, 83(5):1317-1327, 1993.

James Andreoni and Douglas Bernheim. Social image and the $50-50$ norm: A theoretical and experimental analysis of audience effects. Econometrica, 77 (5):1607-1636, 2009.

James Andreoni and John Miller. Giving according to garp: An experimental test of the consistency of preferences for altruism. Econometrica, 70(2):737$753,2002$.

James Andreoni and John Miller. Rational cooperation in the finitely repeated prisoner's dilemma: Experimental evidence. The Economic Journal, 103: 570-585, 1993.

Dan Ariely, Anat Bracha, and Stephan Meier. Doing good or doing well? Image motivation and monetary incentives in behaving prosocially. American Economic Review, 99(1):544-555, 2009.

Gary Becker. A theory of social interactions. Journal of Political Economy, 82 (6):1063-1093, 1974.

Roland Bénabou and Jean Tirole. Incentives and prosocial behavior. American Economic Review, 96(5):1652-1678, 2006.

Boy Scouts of America. Official web site, 2007.

Eleanor Brown and Hamilton Lankford. Gifts of money and gifts of time: Estimating the effects of tax prices and available time. Journal of Public Economics, 47(3):321-341, 1992.

Jeffrey Carpenter. Measuring social capital: Adding field experimental methods to the analytical toolbox. In John Isham and Sunder Ramaswamy, editors, Social Capital and Economic Development: Well-being in developing countries. Edward Elgar, 2002.

Jeffrey Carpenter, Cristina Connolly, and Caitlin Knowles Myers. Altruistic behavior in a representative dictator experiment. Experimental Economics, 11(3):282-298, 2008. 
E. Gil Clary and Mark Snyder. The motivations to volunteer:Theoretical and practical considerations. Current Directions in Psychologial Science, 8(5): 156-159, 1999.

Paul Costa and Robert McCrae. Revised NEO Personality Inventory Manuel (NEO-PI-R) and NEO Five-Factor Inventory (NEO-FFI)professional manual. Psychological Assessment Resources, 1992.

Thomas Dohmen, Armin Falk, David Huffman, and Uwe Sunde. The intergenerational transmission of risk and trust attitudes. IZA Working Paper no. $2380,2006$.

Brian Duncan. Modeling charitable contributions of time and money. Journal of Public Economics, 72(2):213-242, 1999.

Catherine Eckel and Phillip Grossman. Altruism in anonymous dictator games. Games and Economic Behavior, 16(2):181-191, 1996.

Keith Shachat Elizabeth Hoffman, Kevin McCabe and Vernon Smith. Preference, property rights, and anonymity in bargaining games. Games and Economic Behavior, 7(3):346-380, 1994.

Robert Forsythe, Joel Horowitz, N.E. Savin, and Sefton Martin. Fairness in simple bargaining experiments. Games and Economic Behavior, 6(3):347$369,1994$.

Richard Freeman. Working for nothing: The supply of volunteer labor. Journal of Labor Economics, 15(1):S140-S1666, 1997.

Girl Scouts of America. Official web site, 2007.

Jacob Goeree, Charles Holt, and Susan Laury. Private costs and public benefits: Unravelling the effects of altruism and nosey behavior. Journal of Public Economics, 83(2):255-276, 2002.

Patrick Rooney Mark Wilhelm, Eleanor Brown and Richard Steinberg. The intergenerational transmission of generosity. Journal of Public Economics, 92 (10):2146-2156, 2008.

Paul Menchik and Burton Weisbrod. Volunteer labor supply. Journal of Public Economics, 32(2):159-183, 1987.

Phillip Nelson and Kenneth Greene. Signaling Goodness: Social rules and public choice. The University of Michigan Press, 2003.

Thomas Palfrey and Jeffrey Prisbrey. Anomalous behavior in public goods experiments: How much and why? American Economic Review, 70(5):829846, 1997.

Elke Weber, Ann-Renee Blair, and Nancy Betz. A domain-specific risk attitude scale: Measuring risk perceptions and risk behaviors. Journal of Behavioral Decision Making, 15:263-290, 2002.

Susanne Ziemek. Economic analysis of volunteers' motivations: A cross-country study. Journal of Socio-Economics, 35(3):532-555, 2006. 
Figure 1: Sample vanity plate

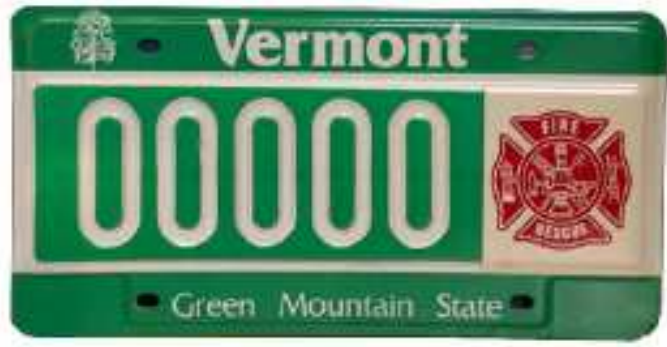

Figure 2: Allocation to charity in dictator game by volunteer status

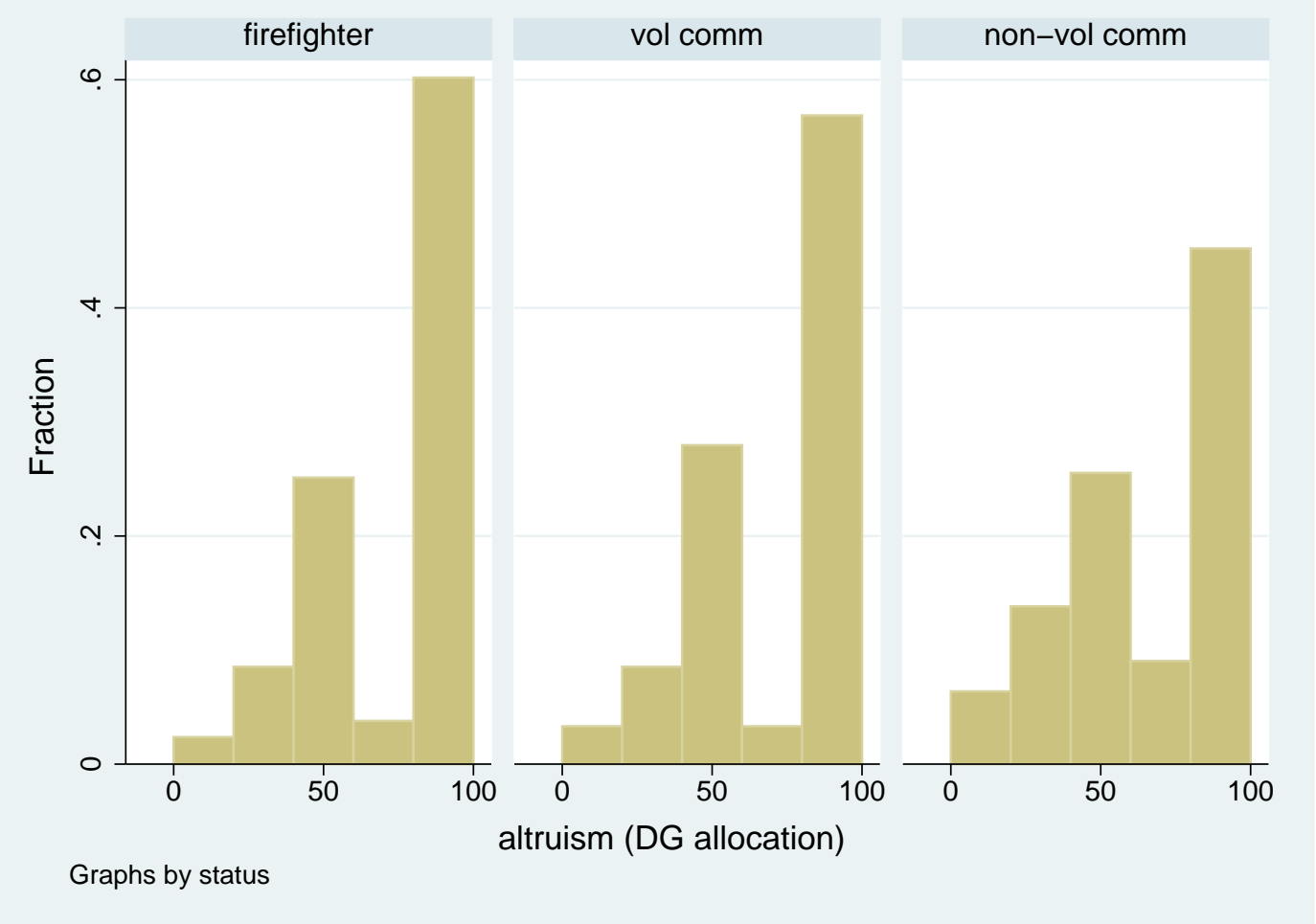


Figure 3: Distribution of error in self-reported hours

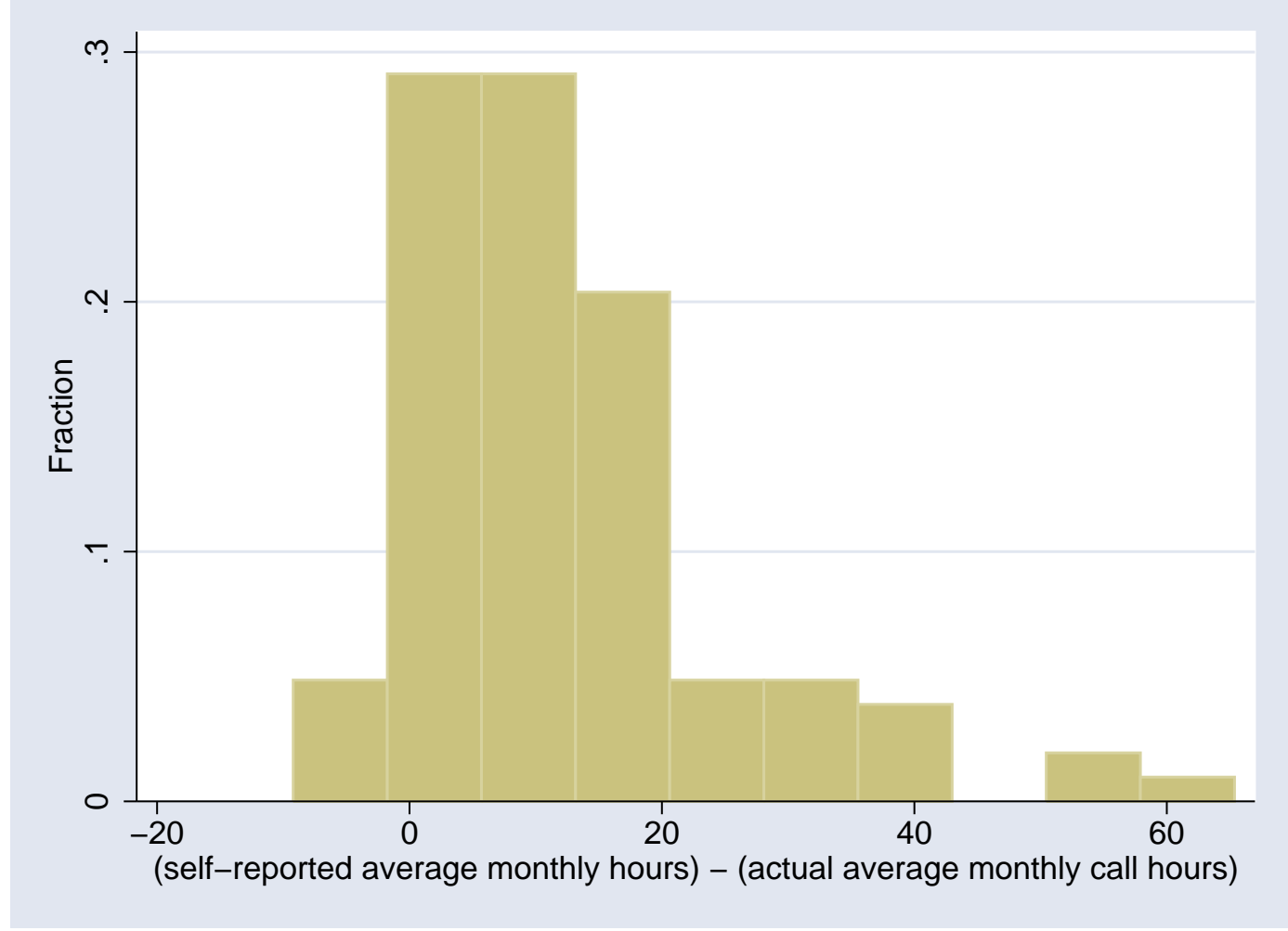


Table 1: Variable descriptions and means

\begin{tabular}{|c|c|c|c|}
\hline variable & description & $\begin{array}{r}\text { volunteer } \\
\text { firefighters }\end{array}$ & $\begin{array}{r}\text { community } \\
\text { members }\end{array}$ \\
\hline \multicolumn{4}{|c|}{ Behavioral factors } \\
\hline altruism & allocation to charity in dictator game $(\$ 0-\$ 100)$ & 77.35 & 67.92 \\
\hline image & I(non-standard ("vanity") license plate) & 0.23 & 0.11 \\
\hline career & $\begin{array}{l}\text { factor score for } 3 \text { questions about volunteering and ca- } \\
\text { reer concerns }\end{array}$ & 0.26 & -0.23 \\
\hline friends1 & volunteering is a good way to make friends (scale 1-5) & 4.60 & 4.10 \\
\hline friends2 & I(friends on fire department prior to joining) & 0.75 & 0.47 \\
\hline extroversion & factor score for 5 extroversion questions & 0.18 & -0.21 \\
\hline risk & factor score for 6 risk questions & 0.32 & -0.14 \\
\hline religious & $\begin{array}{l}\text { I(attends religious services and/or rates religious out- } \\
\text { look as at least somewhat religious) }\end{array}$ & 0.66 & 0.52 \\
\hline family $\mathrm{ff}$ & $\mathrm{I}$ (have family member who is a firefighter) & 0.59 & 0.24 \\
\hline invited & I(have been invited to join local fire department) & 0.67 & 0.12 \\
\hline \multicolumn{4}{|c|}{ Demographics and other factors } \\
\hline residence far & $\mathrm{I}($ home is $>2$ miles from fire station) & 0.35 & 0.40 \\
\hline work far & $\mathrm{I}($ work is $>2$ miles from fire station) & 0.51 & 0.25 \\
\hline age & age in years & 38.61 & 47.99 \\
\hline male & $\mathrm{I}(\mathrm{male})$ & 0.93 & 0.63 \\
\hline student & I(student) & 0.08 & 0.04 \\
\hline married & $\mathrm{I}($ married $)$ & 0.61 & 0.59 \\
\hline children $<=12$ & I(young children at home) & 0.39 & 0.64 \\
\hline children $13-18$ & I(older children at home) & 0.26 & 0.53 \\
\hline$<$ hs education & I(education $<$ high school degree & 0.08 & 0.05 \\
\hline hs education & I(high school degree) & 0.35 & 0.25 \\
\hline$>$ hs education & I(education beyond high school) & 0.57 & 0.70 \\
\hline VT native & I(born in Vermont) & 0.64 & 0.46 \\
\hline employed & I(currently employed $)$ & 0.92 & 0.76 \\
\hline income $<15 \mathrm{k}$ & I(annual household income $<15,000)$ & 0.07 & 0.09 \\
\hline income $15-35 \mathrm{k}$ & I(annual household income 15-35,000) & 0.16 & 0.20 \\
\hline income $35-50 \mathrm{k}$ & I(annual household income $35-50,000)$ & 0.17 & 0.17 \\
\hline income $50-75 \mathrm{k}$ & I(annual household income 50-75,000) & 0.24 & 0.22 \\
\hline income $75-100 \mathrm{k}$ & I(annual household income 75-100,000) & 0.16 & 0.16 \\
\hline income $>100 \mathrm{k}$ & I(annual household income >100,000) & 0.20 & 0.16 \\
\hline wage (if employed) & hourly wage or, for salaried workers, imputed wage & 17.42 & 22.92 \\
\hline donation & amount of household's charitable donations in past year & 469.18 & 799.39 \\
\hline \multicolumn{4}{|c|}{ Firefighter-specific variables } \\
\hline presence of stipend & I(fire department pays hourly stipend for calls) & 0.67 & \\
\hline amount of stipend & $\begin{array}{l}\text { amount of hourly stipend or, for departments that offer } \\
\text { lump sum incentives, imputed hourly stipend }\end{array}$ & 5.34 & \\
\hline call hours & Usual monthly training hours & 10.28 & \\
\hline training hours & Usual monthly call hours & 18.94 & \\
\hline $\mathrm{n}$ & & 217 & 189 \\
\hline
\end{tabular}


Table 2: Probit models of selection into volunteer firefighting

\begin{tabular}{|c|c|c|c|c|c|c|}
\hline & \multicolumn{2}{|c|}{ Model 1} & \multicolumn{2}{|c|}{ Model 2} & \multicolumn{2}{|c|}{ Model 3} \\
\hline & m.e. & s.e. & m.e. & s.e. & m.e. & s.e. \\
\hline altruism (DG allocation) & $0.0017^{*}$ & 0.0010 & 0.0017 & 0.0012 & $0.0052^{* * *}$ & 0.0019 \\
\hline image (vanity plate) & $0.1416^{*}$ & 0.0797 & $0.2308^{* *}$ & 0.0942 & $0.2429 * * *$ & 0.0928 \\
\hline career (factor score) & $0.0706^{*}$ & 0.0428 & -0.0021 & 0.0564 & 0.0016 & 0.0567 \\
\hline friends1 (make friends) & $0.1533^{* *}$ & 0.0617 & $0.2379^{* * *}$ & 0.0733 & $0.2157^{* * *}$ & 0.0717 \\
\hline friends2 (friends on dept) & 0.0253 & 0.0732 & -0.0787 & 0.0820 & -0.0653 & 0.0805 \\
\hline extroversion (factor score) & 0.0405 & 0.0381 & 0.0641 & 0.0448 & 0.0459 & 0.0431 \\
\hline risk (factor score) & $0.1121^{* * *}$ & 0.0356 & 0.0487 & 0.0503 & 0.0313 & 0.0484 \\
\hline religious & $0.1087^{*}$ & 0.0650 & $0.1495^{*}$ & 0.0821 & $0.1566^{* *}$ & 0.0782 \\
\hline family ff & $0.2561^{* * *}$ & 0.0618 & $0.2897^{* * *}$ & 0.0729 & $0.2783^{* * *}$ & 0.0713 \\
\hline invited & $0.5108^{* * *}$ & 0.0523 & $0.4598 * * *$ & 0.0741 & $0.4286^{* * *}$ & 0.0799 \\
\hline demographic controls & \multicolumn{2}{|l|}{ no } & \multicolumn{2}{|c|}{ yes } & \multicolumn{2}{|c|}{ yes } \\
\hline instrumental variables & \multirow{2}{*}{\multicolumn{2}{|c|}{ no }} & \multirow{2}{*}{\multicolumn{2}{|c|}{$\begin{array}{c}\text { no } \\
320\end{array}$}} & \multirow{2}{*}{\multicolumn{2}{|c|}{$\begin{array}{c}\text { yes } \\
314\end{array}$}} \\
\hline $\mathrm{n}$ & & & & & & \\
\hline
\end{tabular}

Demographic controls include age, gender, student status, marital status, children under age 12, children aged 12-18, education level, employment status, income, wage, Vermont native, annual charitable donations, and distance from residence and place of work to fire station. Instruments for altruism in Models 3 are mother allocation, random participant allocation, and scout. ${ }^{*} p<0.10{ }^{* *} p<0.05{ }^{* * *} p<0.01$.

Table 3: Regressions for log training and call hours

\begin{tabular}{|l|cr|cr|}
\hline & \multicolumn{2}{|c|}{ Call Hours } & \multicolumn{2}{c|}{ Training Hours } \\
& coef & s.e. & coef & s.e. \\
\hline altruism (DG allocation) & -0.0016 & 0.0038 & $0.0111^{* *}$ & 0.0052 \\
image (vanity plate) & $0.4016^{*}$ & 0.2333 & 0.0748 & 0.2926 \\
career (factor score) & -0.2189 & 0.1428 & -0.0921 & 0.1960 \\
friends1 (make friends) & 0.0764 & 0.1658 & -0.0458 & 0.2145 \\
friends2 (friends on dept) & 0.2128 & 0.2560 & -0.0781 & 0.3104 \\
extroversion (factor score) & -0.0214 & 0.1420 & 0.1245 & 0.1720 \\
risk (factor score) & 0.1223 & 0.1099 & -0.0644 & 0.1492 \\
religious & -0.1561 & 0.3194 & -0.3659 & 0.3659 \\
family ff & 0.0160 & 0.1777 & -0.0392 & 0.2217 \\
invited & 0.3208 & 0.3610 & 0.3233 & 0.3547 \\
\hline demographic controls & \multicolumn{2}{|c|}{ yes } & \multicolumn{2}{c|}{ yes } \\
instrumental variables & \multicolumn{2}{|c|}{146} & \multicolumn{2}{c}{148} \\
$\mathrm{n}$ & \multicolumn{2}{|c|}{ no } \\
\hline
\end{tabular}

Top 1 percent of hours are dropped from analysis as large outliers. Demographic controls include age, gender, student status, marital status, children under age 12, children aged 12-18, education level, employment status, income, wage, Vermont native, annual charitable donations, years of experience, distance from residence and place of work to fire station, and fixed effects for large stations. ${ }^{*} p<0.10{ }^{* *} p<0.05^{* * *} p<0.01$. 
Table 4: Random effects linear probability models of call response

\begin{tabular}{|c|c|c|c|c|c|c|}
\hline & \multicolumn{2}{|c|}{ Model 1} & \multicolumn{2}{|c|}{ Model 2} & \multicolumn{2}{|c|}{ Model 3} \\
\hline & m.e. & s.e. & m.e. & s.e. & m.e. & s.e. \\
\hline \multicolumn{7}{|l|}{ Call characteristics } \\
\hline spring & $0.0143^{*}$ & 0.0081 & 0.0118 & 0.0083 & 0.0073 & 0.0100 \\
\hline summer & $0.0184^{* *}$ & 0.0076 & $0.0175^{* *}$ & 0.0078 & 0.0108 & 0.0093 \\
\hline fall & $0.0164^{* *}$ & 0.0076 & $0.0169 * *$ & 0.0078 & 0.0020 & 0.0093 \\
\hline weekend & $0.0847^{* * *}$ & 0.0067 & $0.0843^{* * *}$ & 0.0069 & $0.1033^{* * *}$ & 0.0083 \\
\hline typical work hours (8-5) & $-0.0874^{* * *}$ & 0.0061 & $-0.0945^{* * *}$ & 0.0063 & $-0.1042^{* * *}$ & 0.0076 \\
\hline late night (11-5) & $-0.0356^{* * *}$ & 0.0100 & $-0.0313^{* * *}$ & 0.0103 & $-0.0238^{*}$ & 0.0124 \\
\hline fire call & $0.0832^{* * *}$ & 0.0081 & $0.0806^{* * *}$ & 0.0083 & $0.0962^{* * *}$ & 0.0100 \\
\hline calls in last week & $-0.0016^{* *}$ & 0.0008 & $-0.0018^{* *}$ & 0.0009 & $-0.0021^{* *}$ & 0.0010 \\
\hline \multicolumn{7}{|l|}{ Firefighter characteristics } \\
\hline altruism (DG allocation) & & & -0.0004 & 0.0007 & -0.0003 & 0.0009 \\
\hline image (vanity plate) & & & $0.1237^{* * *}$ & 0.0479 & $0.1296^{* * *}$ & 0.0502 \\
\hline career (factor score) & & & $0.0496^{*}$ & 0.0284 & $0.0993^{* * *}$ & 0.0347 \\
\hline friends1 (make friends) & & & -0.0286 & 0.0345 & -0.0442 & 0.0406 \\
\hline friends2 (friends on dept) & & & -0.0320 & 0.0487 & -0.0513 & 0.0497 \\
\hline extroversion (factor score) & & & -0.0158 & 0.0228 & -0.0192 & 0.0214 \\
\hline risk (factor score) & & & -0.0194 & 0.0206 & -0.0070 & 0.0259 \\
\hline religious & & & -0.0466 & 0.0483 & -0.0497 & 0.0551 \\
\hline family ff & & & 0.0565 & 0.0398 & 0.0340 & 0.0418 \\
\hline invited & & & $0.0784^{*}$ & 0.0433 & 0.0300 & 0.0555 \\
\hline department indicators & \multicolumn{2}{|c|}{ yes } & \multicolumn{2}{|c|}{ yes } & \multicolumn{2}{|c|}{ yes } \\
\hline demographic controls & \multirow{2}{*}{\multicolumn{2}{|c|}{$\begin{array}{c}\text { no } \\
22775\end{array}$}} & \multirow{2}{*}{\multicolumn{2}{|c|}{$\begin{array}{c}\text { no } \\
21808\end{array}$}} & \multirow{2}{*}{\multicolumn{2}{|c|}{$\begin{array}{c}\text { yes } \\
15099\end{array}$}} \\
\hline $\mathrm{n}$ & & & & & & \\
\hline
\end{tabular}

Random effects linear probability model of call response. Standard errors are robust. Demographic controls include age, gender, student status, marital status, children under age 12, children aged 12-18, education level, employment status, income, wage, Vermont native, annual charitable donations, and distance from residence and place of work to fire station. ${ }^{*} p<0.10{ }^{* *} p<0.05{ }^{* * *} p<0.01$ 
Table 5: Random effects linear probability models of call response with interaction terms

\begin{tabular}{|l|cc|cc|}
\hline & \multicolumn{2}{|c|}{ Model 4} & \multicolumn{2}{c|}{ Model 5} \\
\hline Call characteristics & m.e. & s.e. & m.e. & s.e. \\
spring & 0.0073 & 0.0100 & 0.0071 & 0.0100 \\
summer & 0.0107 & 0.0093 & 0.0107 & 0.0093 \\
fall & 0.0020 & 0.0094 & 0.0021 & 0.0094 \\
weekend & $0.1033^{* * *}$ & 0.0083 & $0.1033^{* * *}$ & 0.0083 \\
typical work hours (8-5) & $-0.1043^{* * *}$ & 0.0076 & $-0.1043^{* * *}$ & 0.0076 \\
late night (11-5) & $-0.0240^{*}$ & 0.0124 & $-0.0239^{*}$ & 0.0124 \\
fire call & $0.0960^{* * *}$ & 0.0100 & $0.0959^{* * *}$ & 0.0100 \\
calls in last week & $-0.0021^{* *}$ & 0.0010 & $-0.0021^{* *}$ & 0.0010 \\
calls in 2005 & $-0.0004^{* * *}$ & 0.0002 & $-0.0005^{* * *}$ & 0.0002 \\
Firefighter characteristics & & & & \\
altruism (DG allocation) & 0.0001 & 0.0009 & 0.0002 & 0.0009 \\
image (vanity plate) & $0.2684^{* * *}$ & 0.0923 & $0.2775^{* * *}$ & 0.0903 \\
career (factor score) & $0.1123^{* * *}$ & 0.0334 & $0.1064^{* * *}$ & 0.0325 \\
friends1 (make friends) & -0.0331 & 0.0375 & -0.0287 & 0.0373 \\
friends2 (friends on dept) & -0.0577 & 0.0490 & -0.0542 & 0.0481 \\
extroversion (factor score) & -0.0199 & 0.0205 & -0.0213 & 0.0202 \\
risk (factor score) & 0.0002 & 0.0241 & 0.0030 & 0.0235 \\
religious & -0.0626 & 0.0503 & -0.0618 & 0.0492 \\
family ff & 0.0511 & 0.0396 & 0.0468 & 0.0396 \\
invited & 0.0203 & 0.0535 & 0.0128 & 0.0525 \\
Stipend/Reputation interactions & & & & \\
amount of stipend & $0.0197^{* * *}$ & 0.0071 & & \\
amount of stipend*vanity plate & $-0.0207^{*}$ & 0.0121 & & \\
presence of stipend & & & $0.1558^{* * *}$ & 0.0570 \\
presence of stipend*vanity plate & & & $-0.1959^{*}$ & 0.1030 \\
\hline department indicators & \multicolumn{2}{|c|}{ no } & & \multicolumn{2}{|c|}{ no } \\
demographic controls & yes & & 15099 \\
n & \multicolumn{2}{|c|}{15099} & \\
\hline
\end{tabular}

Random effects linear probability model of call response. Standard errors are robust. Demographic controls include age, gender, student status, marital status, children under age 12, children aged 12-18, education level, employment status, income, wage, Vermont native, annual charitable donations, and distance from residence and place of work to fire station. ${ }^{*} p<0.10{ }^{* *} p<0.05{ }^{* * *} p<0.01$ 